\title{
TRÍADES CONCEITUAIS NA EPISTEMOLOGIA DA CIÊNCIA DA INFORMAÇÃO
}

\author{
Niliane Cunha de Aguiar \\ Doutoranda em Ciência da Informação \\ Programa de Pós-Graduação em Ciência da Informação \\ Universidade Federal de Minas Gerais \\ nilianeaguiar@yahoo.com.br
}

\begin{abstract}
Resumo
Por se tratar de uma ciência ainda nos primórdios e que busca sua consolidação epistemológica, os pesquisadores em Ciência da Informação estão construindo seus alicerces metodológicos utilizando sua ligação com as Ciências Sociais para definir sua estrutura paradigmática. Nesse sentido, o presente artigo pretende apresentar o que curiosamente observou-se nos estudos acerca da Ciência da Informação: a existência de diversas tríades conceituais.
\end{abstract}

Palavras-chave

Ciência da Informação. Epistemologia da Ciência da Informação. Tríades Conceituais.

\section{INTRODUÇÃO}

A Ciência da informação, estabelecida na esfera das ciências sociais aplicadas, se caracteriza por sua natureza interdisciplinar e tem buscado ao longo de sua história se institucionalizar através do aprofundamento das percepções acerca de seu objeto de estudo e de suas concepções epistemológicas e ontológicas. Além disso, enfrenta um mundo impactado pela tecnologia e pela busca incessante por conhecimento. Deste modo, acredita-se que, para um melhor entendimento sobre essa Ciência, faz-se necessário encontrar em seus fundamentos teóricos e na metodologia de pesquisa da área um alicerce para o desenvolvimento de novas reflexões que contribuam para o seu fortalecimento.

É necessário ainda analisar suas teorias, campos de atuação, conceitos, relações e princípios, ou seja, sua razão de ser, para melhor compreender suas interações, avanços, deficiências e perspectivas.

Antes de apresentar a Ciência da Informação é preciso tecer algumas considerações a respeito do seu objeto de estudo: a informação. Diversos autores apresentam suas contribuições para a área no sentido de explicar esse objeto, porém, por diversos motivos ainda não se observa um pleno consenso entre esses autores.

A informação é uma abstração informal, declara Setzer (1999), que representa algo significativo para alguém através de um texto, imagem, som ou animação. Para ele, a informação se difere do dado por conter necessariamente uma semântica.

Le Coadic (2004), por sua vez, acredita que existe uma ambiguidade no conceito do termo informação e cita a teoria da 
matemática, a teoria da comunicação e o código genético como exemplos das diferentes disciplinas que o utilizam. Ele conceitua informação como "um conhecimento inscrito (registrado) em forma escrita (impressa ou digital), oral ou audiovisual, em um suporte" (LE COADIC, 2004, p. 4). Já o objetivo da informação, de acordo com o referido autor, é a aquisição de conhecimento, e os documentos são vistos por ele como portadores da informação.

$\mathrm{Na}$ concepção de Robredo (2003), algumas caraterísticas da informação merecem especial atenção: admitir ser registrada de diversas formas; possibilitar sua duplicação e reprodução ad infinito; poder ser transmitida por diversos meios, sendo conservada e armazenada em vários suportes; conseguir ser medida e quantificada; permitir a adição de outras informações, possibilitar sua organização, processamento e reorganização, segundo critérios diversos; e finalmente ter a capacidade de ser recuperada a partir de regras preestabelecidas.

Sobre os estudos e fontes da palavra informação, Capurro e Hjørland (2007) afirmam que existem dois contextos etimológicos do termo, um ligado ao ato de moldar a mente, e outro ao ato de comunicar conhecimento, e, por suas raízes latinas e gregas, os autores acreditam que o prefixo in fortalece a ideia do ato de dar forma a alguma coisa. Consideram que a informação está dirigida para mentes humanas e também é recebida por mentes humanas, mas ressaltam que o surgimento da Ciência da Informação pode ser explicado não somente pelos seres humanos, mas também pela utilização dos sistemas computacionais.

\section{CIÊNCIA DA INFORMAÇÃO}

A respeito do surgimento da Ciência da Informação é importante destacar a existência que diversos autores o investigam, por acreditarem que a sua análise histórica é fundamental, pois, conforme esclarece Black (2006), a reflexão dos contextos históricos da área promove a identidade profissional, aumenta a autocrítica e favorece a avaliação de questões éticas e filosóficas. Baseando-se nessa concepção, é importante destacar que

O surgimento da Ciência da Informação se localiza no movimento de pesquisadores e estudiosos de diversos campos do conhecimento que buscam aglutinar esforços iniciais para solucionar problemas decorrentes do boom bibliográfico e do caos documental (SOUZA, 2008, p. 03).

Entretanto, para Gomes (2008) o surgimento deste campo não se deu como uma área pensada epistemologicamente, mas resultou principalmente da prática dos profissionais que buscaram atender às novas demandas. Desta forma, a autora acredita que, apesar de ainda estar em processo de consolidação, a Ciência da Informação insurge como campo do conhecimento para responder aos desafios apresentados pela sociedade, em consequência do progresso técnico-científico ocorrido principalmente na segunda metade do século XX.

Ortega (2004) também oferece uma importante contribuição para os estudos históricos sobre o campo científico da informação, pois, ao fazer uma exposição da história da Biblioteca e da Biblioteconomia desde o terceiro milênio a.C., evidencia que ao longo do tempo se mantém o objetivo de abrigar todo o conhecimento humano registrado. Além disso, aponta que o impacto provocado pela invenção da imprensa e o desenvolvimento das bibliotecas públicas, e a separação entre Biblioteconomia e Documentação são grandes marcos para a área.

Este cisma entre a Biblioteconomia e a Documentação, para a autora, foi provocado pelo o crescimento das publicações periódicas e pela necessidade de análise de assuntos dos artigos destes periódicos realizada por documentalistas, que se preocupavam não somente com a preservação e organização física dos materiais, mas com o acesso aos conteúdos dos documentos. Sobre essa divisão Shera (1980) ressalta a importância das propostas de Otlet e La Fontaine acerca da análise de conteúdo mais profunda e 
diferenciada da que até então era realizada pelos bibliotecários e que passou a ser denominada documentação.

Também sobre a origem da Ciência da Informação, Saracevic (1992) relata que se deu a partir da revolução científica e técnica iniciada a partir da Segunda Guerra Mundial, com o objetivo de resolver o problema da explosão informacional e, ao passar do tempo, estes problemas informacionais atingiram uma grande importância social.

A partir da década de 50, a busca pela solução para os problemas informacionais foi evidenciada e o termo Recuperação da Informação começou a ser utilizado como respostas para os problemas de descrição intelectual da informação, especificação intelectual da busca informacional e utilização de tecnologias de informação. Desta forma, o trabalho com a recuperação da informação, segundo o mesmo autor, favoreceu o desenvolvimento da Ciência da Informação, como campo científico e profissional e por todos esses benefícios pode ser considerada o componente mais importante da indústria da informação.

O conceito de Ciência da Informação como campo do conhecimento, de acordo com o autor, foi iniciado nos anos 60 e na década de 70 começou a ser afunilado para especificar melhor os fenômenos e processos a serem analisados. Ainda nesta década, os estudiosos da recuperação da informação começaram a enfatizar o papel do usuário, suas interações, e seus processos de comunicação e na década de 80 a Administração também passou a ser inserida nas análises realizadas pela Ciência da Informação.

\section{TRÍADES CONCEITUAIS}

Por se tratar de uma Ciência ainda nos primórdios e que busca sua consolidação epistemológica, os pesquisadores em Ciência da Informação estão construindo seus alicerces metodológicos utilizando sua ligação com as Ciências Sociais para definir sua estrutura paradigmática. Nesse sentido, o presente artigo pretende apresentar o que curiosamente observou-se nos estudos acerca da Ciência da
Informação: a existência de diversas tríades conceituais.

A primeira tríade conceitual que se pode destacar na Ciência da Informação consiste na reflexão acerca dos conceitos de dado, informação e conhecimento. Tal reflexão tem sido tomada como elemento de construção teórica pela disciplina em muitas de suas variadas incursões temáticas, como pode ser percebido por meio da análise dos mapeamentos realizados por Zins (2007).

Nesse sentido, Le Coadic (2004) ressalta que existe uma ambiguidade no conceito do termo informação e citando três exemplos das diferentes disciplinas que $\mathrm{O}$ utilizam: a teoria matemática, a teoria da comunicação e o código.

Já Buckland (1991) estabelece uma tríade conceitual para definir a informação analisando a informação-como-processo; a informação-como-conhecimento e a informação-como-coisa.

Em seguida destacam-se as características estabelecidas por Saracevic (1995) para a Ciência da Informação: a) é interdisciplinar; b) está, inexoravelmente, ligada à tecnologia da informação; e c) tem uma forte dimensão social e humana, acima e além da tecnologia.

Em se tratando de interdisciplinaridade, considerada uma característica crucial da Ciência da Informação, outra tríade marca seu contexto epistemológico no que diz respeito à integração de três áreas: Arquivologia, Biblioteconomia e Museologia (ARAÚJO, 2010). E, a partir dessa integração, surgiu a denominada "Três Marias" expressão cunhada por Smit (1993), ao propor uma simplificação das relações entre as áreas. Para Smit (2002), apesar das diferenças institucionais e profissionais, as três áreas contribuem de forma complementar para a disponibilização da informação.

Também existem pelo menos três perspectivas históricas que procuram explicar as bases da origem da Ciência da Informação, fundamentadas no desenvolvimento de atividades e estudos em seus contornos práticos e teóricos: a Documentação de Paul Otlet (1868-1944), a Biblioteconomia de Jesse 
Shera (1903-1982) e a Recuperação da Informação de Vannevar Bush (1890-1974). A primeira na Europa e as duas últimas nos Estados Unidos (SOUZA, 2008, p. 03).

No que diz respeito ao processo evolutivo da Ciência da Informação, Saracevic (1995) destaca três pressões sofridas pelo campo: a evolução da sociedade, que a cada dia torna o conhecimento o centro das relações econômico-sociais; a aplicação da tecnologia, atualmente indissociável dos serviços e produtos informacionais; e as relações interdisciplinares, responsáveis por uma maior competição entre os campos envolvidos no que se refere aos financiamentos destinados às pesquisas que buscam solucionar os problemas relacionados à informação.

Também sobre os tempos da Ciência da Informação, Barreto (2002) acredita que a Ciência da informação possui três: o primeiro é denominado como tempo da gerência de informações. Datado entre 1945 e 1980, é caracterizado pela necessidade de solucionar problemas de ordenação, organização e controle da explosão informacional. $\mathrm{O}$ segundo momento, denominado tempo da relação informação e conhecimento, deu-se entre 1980 e 1995, sendo caracterizado pelo cognitivismo e pela busca da geração de conhecimento. Por último, o denominado tempo do conhecimento interativo, iniciado a partir de 1995 e existente até os dias de hoje, caracteriza-se pela utilização das tecnologias de informação e comunicação, pelas mudanças por elas geradas, principalmente em relação à velocidade da transferência de informações, e por sua assimilação em tempo real (BARRETO, 2002).

Pinheiro (2006), também divide os tempos da Ciência da Informação em três. Acredita que o primeiro momento denominado fase conceitual e de conhecimento interdisciplinar foi instaurado entre 1961 e 1969; o segundo, chamado de fase de delimitação do terreno epistemológico, durou de 1970 a 1989; e o terceiro, momento existente na década de 90, foi denominado fase de consolidação da denominação e de alguns princípios, métodos e teorias, e aprofundamento da discussão sobre interdisciplinaridade com outras áreas.
Em se tratando dos paradigmas da Ciência da Informação, Almeida et al (2007), aponta três que mais se destacam na Ciência da Informação: o paradigma físico, o cognitivo e o social.

Para os autores, o paradigma físico, focaliza a tecnologia e a mensuração de dados, sem enfatizar o significado semântico. Nessa linha de pensamento, merecem destaque os autores: Vannervar Bush, Shannon e Weaver, Moores, Buckland, Shera e Rayward.

O paradigma cognitivo veio em seguida, para abarcar os modelos mentais dos usuários e o comportamento deste usuário na recuperação de informações. Os principais autores dessa visão, entre outros, são: Marc de May, Belkin, Brookes, Ingwersen, Figueiredo e Vakkari.

E partindo do princípio de que o sujeito não vive isoladamente e que se insere num contexto social, surgiu o paradigma social baseado numa visão sócio cognitiva, ou seja, que passa pela interpretação de uma comunidade que compartilha e constrói conhecimento. Os principais adeptos dessa linha são: Capurro, Hjørland, Swales e Le Coadic (ALMEIDA et al, 2007).

A Ciência da Informação também desenvolve teorias acerca da gestão informacional, nas quais destacam-se as ideias de Choo (2003), que propõe para análise do comportamento informacional dos usuários um fluxo de três arenas interligadas que se complementam e se alimentam mutuamente por meio de uma visão holística do uso da informação:

\footnotetext{
- $1^{a}$ arena: criar significado - se relaciona à interpretação das informações recebidas;

- $2^{\mathrm{a}}$ arena: construir conhecimento consiste na articulação entre os conhecimentos prévios do usuário e a interpretação das novas informações recebidas, que geram segundo $\mathrm{Choo}$ (2003, p. 50) "novos produtos ou novas competências";

- $3^{\mathrm{a}}$ arena: tomar decisões - nesse momento o conhecimento adquirido fornece uma base intelectual, que capacita o usuário a escolher o melhor uso que poderá fazer das informações assimiladas.
} 
Nesses estudos sobre busca e uso da informação, Choo (2006) também destaca mais três aspectos: dimensões situacionais, necessidades cognitivas e reações emocionais.

As dimensões situacionais representam o meio social ou profissional do indivíduo, assim como os tipos de problemas que enfrenta e até mesmo o modo de resolver esses problemas num determinado contexto no qual ocorre o uso da informação, com regras e normas que moldam os comportamentos, através dos quais a informação tornar-se-á útil.

As necessidades cognitivas representam, por sua vez, a capacidade do indivíduo de produzir sentido (criar significados) através de processos lógicos de percepção, compreensão, seleção, análise e interpretação da realidade e do mundo em que vive.

Já as reações emocionais, para o autor, influenciam o processo de busca de informação, pois canalizam a atenção para determinados tipos de informação, destacam opiniões, gostos e aversões ou revelam dúvidas e incertezas.

Outra vertente, apresentada por González de Gómez (2000a, 2000b, 2001), que indaga as ações que constituem o valor da informação, acredita que a produção de um valor de informação se daria em um circuito constituído por três planos, cada qual com diversas camadas: o plano informacional, o plano metainformacional e o plano dos dispositivos.

No âmbito da pesquisa em arquitetura da informação, Rosenfeld e Morville (2006) destacam a importância do trio: usuário (necessidade, tarefas, hábitos e comportamentos), conteúdo (objetivo, uso, volume, formato, estrutura, governança, dinamismo) e contexto (valor, cultura, política, restrições tecnológicas, localização, dentre outros).

No entanto, algumas dificuldades de pesquisa na área também podem ser observadas, dentre as quais Ortega (2004) destaca: a descontextualização dos conceitos do termo informação utilizados, a fragmentação e a falta de reconhecimento de campos constituídos e também aplicados. Isto, de acordo com a autora, cria um obstáculo para a compreensão teórica da área e, consequentemente, para seu desenvolvimento.

Em seu diálogo crítico, Marteleto $(1995,2001)$ não ignora as ações que visam à conformação da diversidade de sentidos encontrados nos contextos sociais a um sentido hegemônico, em que a informação aparece como bem simbólico com papel central na sociedade contemporânea, mas questionava o hiato de estudos de um vasto território, no plano das redes de relações sociais.

A crítica da autora se dá por meio de três frentes: a primeira recai sobre a não compreensão no campo da Ciência da Informação deste papel simbólico com fins hegemônicos da informação capturada, filtrada, ordenada e disponibilizada pelos sistemas oficiais (a escola, o Estado, os jornais etc.); a segunda sobre a ausência de pesquisas sobre as apropriações destas informações que se realizam no contexto das práticas nas redes sociais, ou o para que usam a informação; e finalmente e articulada a estas, destaca a consequente exclusividade dos conhecimentos que são produzidos no campo a partir da concepção da informação enquanto entidade autonomizada, que serviriam como uma espécie de conhecimento disponibilizado sobre meios e modos de sua captura, filtragem, ordenação e disponibilização, ficando ao dispor para as ações de controles centralizados de sentidos (FERNANDES, 2012).

Para finalizar, outras dificuldades podem ser apontadas, pois, conforme explica Paim (2001, p. 21), no que se refere à interdisciplinaridade da Ciência da Informação, observa-se que apesar de importar conhecimentos de outras áreas, é questionável se o processo de incorporação realmente ocorre na estrutura desta, uma vez que a interdisciplinaridade não tem sido praticada "no sentido da fertilização mútua dos saberes, e assim o que acontece na prática é a justaposição de conceitos das diversas disciplinas".

A causa de tal realidade para a autora pode estar na convergência de três fatos: o fenômeno contemporâneo da informação; o avanço da tecnologia da informação e o aumento exponencial da produção de 
conhecimento e/ou informação, que está permeando todas as áreas. Desse modo, é possível que tudo isso tenha gerado um caos no qual os cientistas da informação, ainda não estão sabendo conviver.

\section{CONSIDERAÇÕES FINAIS}

Novas tendências estão surgindo na Ciência da Informação, conforme afirma Araújo (2009), pois a interação com as ciências hermenêuticas estão dando novo rumo às pesquisas, uma vez que essas ciências valorizam a interpretação das pessoas acerca dos fenômenos. Além disso, a aproximação recente da Ciência a Informação com a semiótica e também sua contribuição às análises políticas e econômicas abrem novos caminhos para os pesquisadores da área. Assim, já é possível observar o surgimento do interesse pelas características sociais da informação, pela filosofia da informação, pelas políticas de informação e por suas abordagens fenomenológicas. E assim, pressupõe-se que outras tríades estão por vir...

\title{
CONCEPTUAL TRIADS IN EPISTEMOLOGY OF INFORMATION SCIENCE
}

\begin{abstract}
Because it is a science in its infancy and its epistemological quest consolidation, researchers in information science are building their methodological foundations using their connection with the social sciences to define its paradigmatic structure. In this sense the present article intends to present the interestingly been observed in studies of information science: the existence of different conceptual triads.
\end{abstract}

Keywords

Information Science. Epistemology of Information Science. Conceptual Triads.

Artigo recebido em 24/11/2013 e aceito para publicação em 11/03/2014

\section{REFERÊNCIAS}

ALMEIDA, D. P. R. et al. Paradigmas Contemporâneos da Ciência da Informação: a recuperação da informação como ponto focal. Revista Eletrônica Informação e Cognição, v.6, n.1, p.16-27, 2007.

ARAÚJO, C.A. A. Ciência da Informação como campo integrador para as áreas de Biblioteconomia, Arquivologia e Museologia. Inf. Inf., Londrina, v. 15, n. 1, p. 173 - 189, Jul./Jun. 2010.

Correntes teóricas da ciência da informação. Ciência da Informação, Brasília, v.38, n.3, p.192-204, set./dez.2009.
BARRETO, A. A. A condição da informação. São Paulo em Perspectiva, São Paulo, v.16, p.67-74. 2002.

BLACK, A. Information history. Annual

Review of Information Science and

Technology, Arizona, v.40, n.1, p.441- 473. 2006.

BUCKLAND, M. K. Informação como coisa.

Journal of the American Society for

Information Science (JASIS), v.45, n.5, p.351-360.1991.

CAPURRO, R.; HJØRLAND, B. O conceito de informação. Perspectivas em Ciência da Informação, Belo Horizonte, v.12, n.1, 2007. Disponível em:

$<$ http://www.eci.ufmg.br/pcionline $>$. Acesso em: 28 out. 2013. 
CHOO, C. W. A organização do conhecimento. São Paulo: SENAC, 2003.

The Knowing organization: How organizations use information to construct meaning, create knowledge, and make decisions. Oxford University Press, New York, 2006.

FERNANDES, G. C.. Contribuições de Marteleto e González de Gómez ao entendimento do Informacional: diálogos com três aportes da informação. Ponto de acesso, Salvador, V.6, n.1 ,p. 2-31, abr. 2012.

GOMES, M. Y. F. S. F. Ciência da Informação: desafios atuais para a consolidação de um campo. In: ENCONTRO NACIONAL DE PESQUISA EM CIÊNCIA DA INFORMAÇÃO (ENANCIB), 9, 2008, São Paulo. Anais... São Paulo, out. 2008.

Disponível em

$<$ http://www.ancib.org.br/media/dissertacao /2004.pdf $\geq$. Acesso em: 13 jul. 2011.

GONZÁLEZ DE GÓMEZ, M. N. O caráter seletivo das ações de informação.

Informare, Rio de Janeiro, v. 5, n. 2, p. 7-31, 2000a.

da Ciência da

Metodologia de pesquisa no campo

Informação. DataGramaZero: Revista de Ciência da Informação v.1, n.6, dez 2000b.

Disponível em:

<http://www.dgz.org.br/dez00/Art_03.htm> . Acesso em: 22 mar. 2003.

Para uma reflexão epistemológica

acerca da Ciência da Informação.

Perspectivas em Ciência da Informação, Belo Horizonte, v.6, n.1, p. 5-18, 2001.

Disponível em:

$<$ http://portaldeperiodicos.eci.ufmg.br/index. $\mathrm{php} / \mathrm{pci} /$ article/viewFile/433/243>. Acesso em: 25 jul. 2008.

LE COADIC, Y. F. A ciência da

informação. Brasília: Briquet de Lemos, 2004.
MARTELETO, R. M. Confronto simbólico, apropriação do conhecimento e produção de informação nas redes de movimentos sociais. Datagramazero: Revista de Ciência da Informação, Rio de Janeiro, v. 2, n. 1, fev. 2001.

Cultura, educação, distribuição social dos bens simbólicos e excedente informacional. Informare, v. 1, n. 2, p. 11-23, jul./dez. 1995.

ORTEGA, C. D. Relações históricas entre Biblioteconomia, Documentação e Ciência da Informação. DataGramaZero: Revista de Ciência da Informação, Rio de Janeiro, v.5, n.5, p.3, 2004. Disponível em: $<$ http://www.dgz.org.br/out04/Art_03.htm $\geq$. Acesso em: 08 mai. 2013.

PAIM, I. Interdisciplinaridade na ciência da informação: início de um diálogo.

Perspectivas em Ciência da Informação, Belo Horizonte, v. 6, n. 1, p. 19-26, jan./jun. 2001.

PINHEIRO, L. V. R. Ciência da

Informação: desdobramentos disciplinares, interdisciplinaridade e transdisciplinaridade. 2006. Disponível em: $<$ http://www.uff.br/ppgci/editais/lenavaniale ituras.pdf $>$. Acesso em: 05 jun.2013.

ROBREDO, J. Informação, conhecimento e ciência da informação. In: Da ciência da informação revisitada aos sistemas humanos de informação. Brasília: Thesaurus, 2003. p.1-26.

ROSENFELD, L.; MORVILLE, P. Information Architecture for the World Wide Web. 3. ed. Sebastopol, CA: O'Reilly, 2006.

SARACEVIC, T. Information science: origin, evolution and relations In:

Conceptions of library and information science: historical, empirical and theoretical perspectives. London: Taylor Graham, c1992. p. 5-27. 
Interdisciplinarity nature of

Information Science. Ciência da Informação.

Brasília, v.24, n.1, p.36-41,1995. Tradução de

Durval de Lara Filho.

SETZER, V. Dado, informação,

conhecimento e competência.

DatagramaZero: Revista de Ciência da

Informação, n. zero, dez. 1999. p. 1-12.

Disponível em:

<http://www.dgz.org.br/dez99/Art_01.htm>

. Acesso em: 30 jul. 2012.

SHERA, J. H. Sobre Biblioteconomia, Documentação e Ciência da Informação. In: GOMES, H. E. Ciência da Informação ou informática? Rio de Janeiro: Calunga, 1980. p. 91-105.

SMIT, J. Arquivologia, biblioteconomia e museologia: o que agrega estas atividades profissionais e o que as separa? Revista

Brasileira de Biblioteconomia e

Documentação, São Paulo, Nova Série, v. 1, n.2, p. 27-36, fev. 2002.
. O documento audiovisual ou a

proximidade entre as três Marias. Revista

Brasileira de Biblioteconomia e

Documentação, 26, 1, 1993, 81-85.

SOUZA, E. D. Dimensões teóricometodológicas da Ciência da Informação: dos desafios à consolidação epistemológica. In: ENCONTRO NACIONAL DE PESQUISAEM CIÊNCIA DA

INFORMAÇÃO (ENANCIB), 9, 2008, São

Paulo. Anais... São Paulo, out. 2008.

Disponível em:

<http://www.ancib.org.br/media/dissertacao /1576.pdf $\geq$. Acesso em: 13 jul. 2013.

ZINS, C. Conceptual approaches for defining data, information, and knowledge. Journal of the American Society for Information Science and Technology, New York, v.58, n.4, p.479-493. 2007. 